Surgery for

Congenital

Heart Disease

\title{
Supraventricular tachyarrhythmias in Ebstein anomaly: Management and outcome
}

Anant Khositseth, MD, ${ }^{a}$ Gordon K. Danielson, MD, ${ }^{b}$ Joseph A. Dearani, MD, ${ }^{b}$ Thomas M. Munger, MD, ${ }^{c}$ and Coburn J. Porter, MD

From the Department of Pediatric and Adolescent Medicine, Division of Pediatric Cardiology, ${ }^{a}$ the Division of Cardiovascular Surgery, ${ }^{b}$ and the Division of Cardiovascular Diseases and Internal Medicine, ${ }^{c}$ Mayo Clinic, Rochester, Minn.

Presented at the American College of Cardiology meeting in Chicago, Ill, March 30April 2, 2003.

Received for publication Nov 27, 2003; revisions received Jan 20, 2004; accepted for publication Feb 6, 2004.

Address for reprints: Coburn J. Porter, MD, Pediatric Cardiology, Mayo Clinic, Rochester, MN 55905 (E-mail: cporter@ mayo.edu).

J Thorac Cardiovasc Surg 2004;128:826-33

$0022-5223 / \$ 30.00$

Copyright $\odot 2003$ by The American Association for Thoracic Surgery

doi:10.1016/j.jtcvs.2004.02.012

Objective: This study was undertaken to review the role of electrophysiology testing and to determine the early and late results of medical and surgical management of supraventricular tachyarrhythmias in Ebstein anomaly.

Methods: We reviewed 130 patients between 1990 and 2001 with Ebstein anomaly and history of tachyarrhythmia with a median age of 25 years (mean age 27.5 years); 106 underwent electrophysiologic testing and 24 had documented atrial flutter or fibrillation. We excluded 21 patients: negative results of testing $(n=18)$, ventricular tachycardia ( $n$ $=2)$, and junctional tachycardia $(\mathrm{n}=1)$. The remaining 109 patients had more than one mechanism: accessory pathway-mediated tachycardia $(\mathrm{n}=49)$, atrioventricular nodal reentrant tachycardia $(\mathrm{n}=10)$, and atrial flutter/fibrillation $(\mathrm{n}=70)$.

Results: Eighty-three patients underwent at least one arrhythmia procedure combined with surgery for Ebstein anomaly. Early mortality was 4.8\%. Forty-one patients underwent surgical ablation of an accessory pathway without recurrent accessory pathwaymediated tachycardia at a mean follow-up of 48 months. Seven patients underwent surgical perinodal cryoablation for atrioventricular nodal reentrant tachycardia without recurrence at a mean follow-up of 57 months. Forty-eight patients underwent surgical intervention for atrial flutter or fibrillation (right-sided maze procedure, $\mathrm{n}=38$, and cryoablation of the atrial isthmus, $\mathrm{n}=10$ ). Freedom from recurrent atrial flutter or fibrillation was $75 \%$ at a mean follow-up of 34 months.

Conclusion: Concomitant arrhythmia procedures can be performed without increase in early mortality and should be added to Ebstein repairs for all patients who have supraventricular tachyarrhythmias. Surgical procedures for accessory pathwaymediated tachycardia and atrioventricular nodal reentrant tachycardia give excellent (100\%) freedom from recurrence of those arrhythmias. Surgical intervention for atrial flutter/fibrillation yields freedom from late recurrence in $75 \%$ of cases.

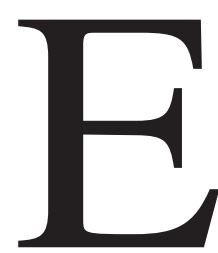

bstein anomaly (EA) was first described in 1866 by Wilhelm Ebstein after examination of the heart of a cyanotic 19-year-old laborer who died of tricuspid regurgitation related to a severe malformation of the tricuspid valve. ${ }^{1-3}$ EA is characterized by spiral displacement of the posterior and septal leaflets downward toward the apex of the right ventricle and is often associated with an atrial septal defect or other cardiac anomaly. ${ }^{4}$ It is an uncommon congenital cardiac malformation accounting for fewer than $1 \%$ of congenital heart defects. The pathologic abnormalities in EA, including a markedly enlarged right atrium and right ventricle as well as associated 
atrioventricular (AV) accessory conduction pathways (APs), provide the substrate for the development of both supraventricular and ventricular tachyarrhythmias. APmediated reciprocating tachycardia (APMT), AV nodal reentrant tachycardia (AVNRT), and atrial flutter or fibrillation $(\mathrm{AFl} / \mathrm{F})$ are the most common supraventricular tachyarrhythmias found in this anomaly. Preexcitation and Wolff-Parkinson-White syndrome are more frequently associated with this anomaly (10\%-29\%) than any other congenital heart defect. ${ }^{5,6}$ At least $15 \%$ of patients with EA experience episodes of paroxysmal supraventricular tachycardia. ${ }^{6,7}$ Although current operations for EA, which include tricuspid valve repair or replacement with correction of associated defects, are highly successful and yield excellent early and late results,${ }^{8-10}$ long-term outcome is still importantly affected by the patient's cardiac rhythm. The objectives of this study were to review the role of electrophysiologic testing in patients with EA associated with supraventricular tachyarrhythmias and to determine the early and late results of medical and surgical interventions for those arrhythmias.

\section{Methods}

\section{Study Population}

From March 1, 1990, through October, 2001, we evaluated 130 patients (79 female) with EA and a history of tachyarrhythmias at Mayo Clinic, Rochester, Minnesota. Diagnosis of EA was confirmed by echocardiography, which showed displacement and tethering of the septal and posterior leaflets of the tricuspid valve. ${ }^{11-13}$ Patient age ranged from 9 months to 70 years (mean $27.5 \pm 18.0$ years, median 25 years).

Patients were evaluated by review of available electrocardiograms (ECGs), and selected patients were referred for invasive electrophysiologic testing. All patients with ECG evidence of preexcitation underwent electrophysiologic testing to identify the location and characteristics of their pathways. A total of 106 patients underwent electrophysiologic testing; 24 who had documented $\mathrm{AFl} / \mathrm{F}$ according to baseline ECG or history were not studied.

Twenty-one patients were excluded from subsequent review: 18 with negative results of electrophysiologic testing, 2 with inducible ventricular tachycardia only, and 1 with inducible junctional tachycardia only. The records of the remaining 109 patients were reviewed retrospectively. These patients had mechanisms of supraventricular tachyarrhythmias as follows: 49 with APMT, 10 with AVNRT, and 70 with AFI/F. Eighteen patients had multiple mechanisms of supraventricular tachyarrhythmia (Figure 1).

Demographic and other patient-related data were obtained from medical records. Recent follow-up information was obtained from patient questionnaires, subsequent clinic visits, and written correspondence with local physicians. Telephone interviews were obtained from patients or families who did not respond to the questionnaires. This study was approved by the Mayo Foundation institutional review board, and patients or parents gave informed written consent.

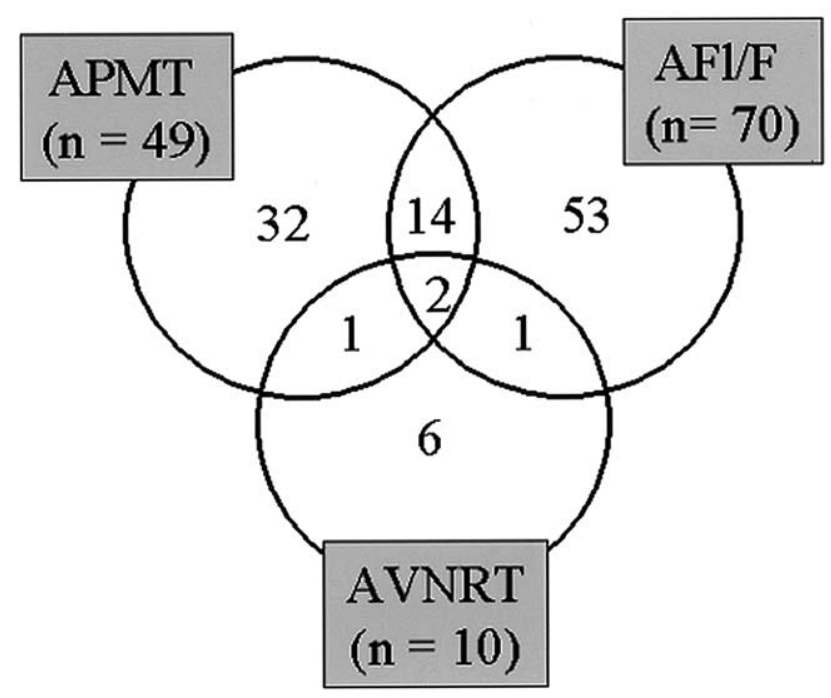

Figure 1. Distribution of 129 arrhythmias in 109 patients.

\section{Statistical Analysis}

Continuous variables were expressed as range, mean $\pm \mathrm{SD}$, and median. Survival free from recurrent AFI/F was estimated according to the Kaplan-Meier method. The log-rank test was used for univariate analysis of type of surgical procedure for $\mathrm{AFI} / \mathrm{F}$ (rightsided maze procedure or cryoablation) on the rate of recurrence. Early mortality was defined as death occurring within 30 days of operation or at any time during the index hospitalization.

\section{Surgical Technique}

Some weak APs cease to function when the heart is cooled, when cardiopulmonary bypass is instituted, or after administration of cardioplegia. Accordingly, for patients with APMT, intraoperative electrophysiologic mapping was begun at normothermia $\left(37^{\circ} \mathrm{C}\right)$ before institution of cardiopulmonary bypass. A multielectrode sock was placed over the ventricles during sinus rhythm or atrial pacing, and a multielectrode band was placed on the atrial side of the AV groove during ventricular pacing or APMT. Points of earliest activation were displayed on a computer template (Bard Electrophysiology; C. R. Bard, Inc, Murray Hill, NJ). When necessary, endocardial mapping on the atrial side of the tricuspid valve annulus, ventricular septum, or both, was accomplished with cardiopulmonary bypass that was established at normothermia. To avoid loss of function of weak APs, administration of cold blood cardioplegic solution was avoided until intracardiac mapping was completed. The ascending aorta was temporarily crossclamped as the right atrium was opened, and all atrial and ventricular septal defects were rapidly closed. Any air on the left side was then aspirated, the crossclamp was removed, and the heart was allowed to be perfused and beating. The AV junction was mapped with a rigid probe, and points of earliest atrial activation were noted during ventricular pacing or APMT. Surgical ablation of the APs was performed during cardioplegic arrest. Transmural incisions were made in the right atrium $2 \mathrm{~mm}$ from the tricuspid annulus and carried $1 \mathrm{~cm}$ down over the right ventricle. ${ }^{14}$ The dissected areas were lightly electrocoagulated and repaired by suture. For APs 


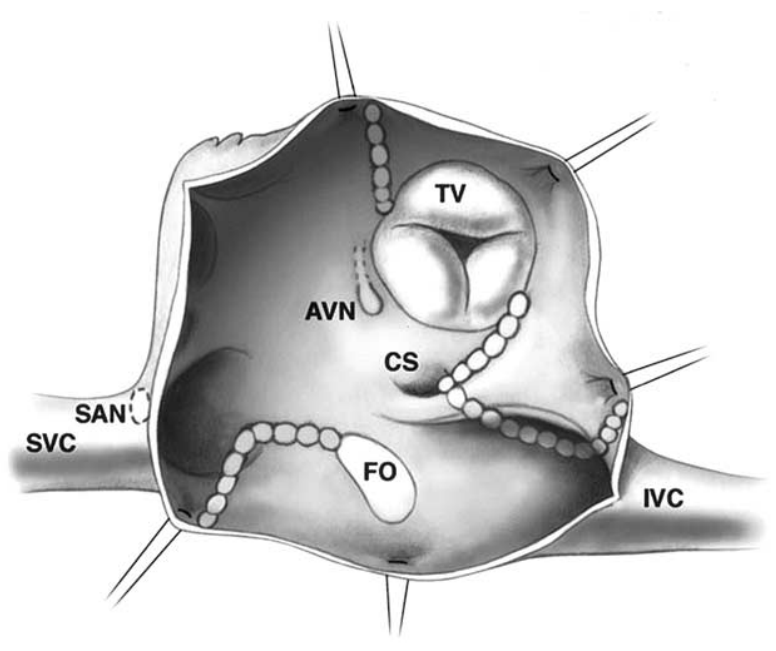

Figure 2. Location of cryoablation blocking lines for AFI/F. See text for details. TV, Tricuspid valve; AVN, AV node; CS, coronary sinus; $S A N$, sinoatrial node; $S V C$, superior vena cava; $F O$, foramen ovale; IVC, inferior vena cava.

near the conduction system, cryoablation was often used with the heart beating to avoid permanent heart block. Repair or replacement of the tricuspid valve was then carried out, together with repair of all associated anomalies. When a valve repair was performed, the heart was kept arrested and the field was kept bloodless to optimize exposure of the anatomy. For tricuspid valve replacement, the crossclamp was removed after suture placement had been completed in the region cephalad to the conduction tissue, and the heart was then allowed to be perfused and beating. ${ }^{15}$ After discontinuation of cardiopulmonary bypass, repeat electrophysiologic testing was performed to test for residual AP function or inducible APMT. Temporary atrial and ventricular pacing wires were placed before sternal closure. When feasible, patients undergoing surgical ablation of APs had electrophysiologic testing performed through their temporary atrial and ventricular pacing wires before discharge from the hospital.

For patients with AVNRT, perinodal cryoablation was performed after institution of cardiopulmonary bypass, right atriotomy, and closure of intracardiac septal defects (Frigitronics of Connecticut, Shelton, Conn). Multiple applications of the cryoprobe (freezes) were made at $-70^{\circ} \mathrm{C}$ for 60 seconds around and within the coronary sinus and then carried anteriorly toward the proximal AV node until temporary complete heart block was noted, at which time rewarming was begun immediately. In all cases, normal AV conduction returned shortly thereafter. When indicated, supplemental freezes were made superior and anterior to the AV node and bundle of His.

For patients with $\mathrm{AFl} / \mathrm{F}$, two techniques were used. For most patients without previous cardiac surgery, a right-sided maze procedure was performed as previously described elsewhere. ${ }^{16}$ If there were dense adhesions as a result of previous cardiac surgery, a cryoablation procedure, which included the right atrial isthmus, was performed instead to minimize dissection, expedite the procedure, and lessen postoperative bleeding. Multiple cryoprobe freezes were placed to produce blocking lines across the right atrial isthmus from the posterolateral tricuspid annulus to the coronary sinus to the inferior vena cava and the inferior atriotomy. Additional blocking lines were placed from the anterolateral tricuspid annulus to the superior atriotomy and from the fossa ovalis to the superior vena cava and superior atriotomy (Figure 2). Each freeze was made at $-70^{\circ} \mathrm{C}$ for 60 to 90 seconds, depending on the thickness of tissue beneath the freezing probe.

Repair or replacement of the tricuspid valve was then performed, and associated cardiac anomalies were repaired. At the conclusion of the operation, redundant right atrium was resected (right reduction atrioplasty) to reduce the right atrium to normal size.

\section{Results}

Of 109 patients, 84 (77\%) underwent tricuspid valve replacement, 18 (17\%) underwent tricuspid valve repair, and $7(6 \%)$ had no operation. Overall, early operative mortality was $7(6.9 \%)$ of 102 patients. Eighty-three patients had combined arrhythmia and EA corrective surgery; early mortality in this subset was $4(4.8 \%)$ of 83 patients. This was not significantly different from the early mortality for patients who underwent EA corrective surgery only (3/19 patients, $15.8 \%, P=.13$ ).

In the APMT group (Table 1), 13 patients had undergone one to three previous unsuccessful attempts at radiofrequency ablation elsewhere $(n=11)$ or at our institution $(n=2)$. One of these had a stroke and another had a deep vein thrombosis at the time of attempted ablation. Forty patients had a single AP, one of which was weakly conducting with a location that could not be identified. Nine patients had two APs. Right posterolateral free wall was the most common location, followed by posteroseptal and right posterior free wall locations (Figure 3). Although uncommon, Mahaim fiber-mediated tachycardia $(\mathrm{n}=2)$ and permanent form of junctional reciprocating tachycardia $(n=1)$ were found in some of our patients. None of the APs was located on the left side of the heart.

All 49 patients underwent electrophysiologic testing: 9 preoperative testing only, 10 intraoperative testing only, and 30 both preoperative and intraoperative testing. In 1 of the 30 patients, the AP could not be mapped intraoperatively; surgical ablation was therefore performed according to the preoperative mapping results. Fifteen of the remaining 29 patients $(52 \%)$ had concordance between the preoperative and intraoperative mapping with regard to number and location of APs.

In the AVNRT group (Table 1), 3 patients had both APMT and AVNRT; 1 of them had manifest preexcitation. In the AFl/F group (Table 1), 23 patients (33\%) had undergone previous cardiac operations. Management of each arrhythmia mechanism is summarized in Figure 4.

\section{Management of APMT $(n=49)$}

No intervention for $\boldsymbol{A P}(\boldsymbol{n}=4)$. Four patients had no intervention for AP because the pathway had a long effec- 
tive refractory period and there was no inducible reciprocating tachycardia. Three of these did not require EA corrective surgery because of mild tricuspid regurgitation. A fourth patient underwent tricuspid valve replacement and atrial septal defect closure; death occurred on the first operative day from intractable right ventricular failure. The 3 survivors have had follow-ups of 100, 134, and 142 months; none had recurrence of APMT.

Radiofrequency ablation for AP $(n=6)$. Six patients underwent attempted radiofrequency ablation procedures at our institution, 4 of which were successful without death or complication. In these 4 patients, the AP was located in the right posterolateral free wall $(\mathrm{n}=3)$ or posteroseptal region $(\mathrm{n}=1)$. Two patients with successful ablation subsequently underwent EA corrective surgery with tricuspid valve replacement. All 4 patients were in sinus rhythm without preexcitation at the time of hospital discharge. The 2 patients with unsuccessful catheter ablation were found to have their APs located in the right posterolateral free wall when the pathways were subsequently mapped and divided at the time of EA corrective surgery. Two of the 4 patients who underwent successful catheter ablation have been followed up for 18 and 45 months without recurrence of APMT. The remaining 2 patients were unavailable for follow-up.

Surgical ablation of AP $(n=41)$. All 41 patients $(100 \%)$ had successful surgical intervention for AP at the time of EA corrective surgery: surgical division $(n=26)$, cryoablation $(\mathrm{n}=4)$, and combined surgical division and cryoablation $(\mathrm{n}=11)$. Postprocedure intraoperative electrophysiologic testing demonstrated no evidence of either AP function or inducible APMT. There was one early death from intractable right ventricular failure despite hemodynamic support with an intra-aortic balloon pump and a right ventricular assist device. $\mathrm{He}$ had no postoperative arrhythmia.

One patient who had undergone 3 previous attempts at catheter radiofrequency ablation elsewhere had complete heart block develop on the second postoperative day. A permanent pacemaker was placed; on follow-up, her rhythm was predominantly normal AV conduction. Other nonfatal complications included hypotension requiring intra-aortic balloon pump placement $(\mathrm{n}=1)$, cardiac tamponade $(\mathrm{n}=$ $1)$, and pericardial effusion $(\mathrm{n}=1)$. Postoperative arrhythmias included junctional rhythm $(n=3)$, transient junctional ectopic tachycardia $(\mathrm{n}=1)$, and nonsustained ventricular tachycardia $(\mathrm{n}=1)$.

Discharge ECGs demonstrated sinus rhythm without preexcitation $(\mathrm{n}=37)$, junctional rhythm $(\mathrm{n}=2)$, and electronic dual-chamber pacing $(\mathrm{n}=1)$. Discharge electrophysiologic testing was performed in 28 patients; all had no evidence of AP function or inducible arrhythmia.
TABLE 1. Patient data and surgical procedures stratified according to mechanism of arrhythmia

\begin{tabular}{|c|c|c|c|}
\hline & $\begin{array}{c}\text { APMT } \\
(n=49)\end{array}$ & $\begin{array}{c}\text { AVNRT } \\
(n=10)\end{array}$ & $\begin{array}{c}\text { AF1/F } \\
(\mathbf{n}=70)\end{array}$ \\
\hline Female/male ratio & $30: 19$ & $7: 3$ & $40: 30$ \\
\hline \multicolumn{4}{|l|}{ Age $(y)$} \\
\hline Mean $\pm S D$ & $18.4 \pm 13.1$ & $19.7 \pm 14.5$ & $33.4 \pm 18.1$ \\
\hline Median & 16 & 18 & 35 \\
\hline Range & $0.75-50$ & $1-44$ & $1-68$ \\
\hline \multicolumn{4}{|l|}{ Baseline ECG (\%) } \\
\hline Sinus rhythm & 100 & 100 & 86 \\
\hline With preexcitation & 78 & 10 & 0 \\
\hline $\mathrm{AF} 1 / \mathrm{F}$ & 0 & 0 & 14 \\
\hline \multicolumn{4}{|l|}{ Arrhythmia symptoms (\%) } \\
\hline Palpitation & 65 & 90 & 84 \\
\hline Syncope & 25 & 10 & 25 \\
\hline Presyncope & 12 & 10 & 7 \\
\hline Dizziness & 12 & 0 & 29 \\
\hline Transient ischemic attack & 4 & 10 & 3 \\
\hline Out-of-hospital arrest & 0 & 10 & 0 \\
\hline None & 14 & 0 & 0 \\
\hline \multicolumn{4}{|l|}{ EA corrective surgery (\%) } \\
\hline $\begin{array}{l}\text { Tricuspid valve } \\
\text { replacement }\end{array}$ & 69 & 70 & 77 \\
\hline Tricuspid valve repair & 20 & 0 & 23 \\
\hline $\begin{array}{l}\text { Atrial septal defect } \\
\text { closure }\end{array}$ & 71 & 60 & 49 \\
\hline $\begin{array}{l}\text { Patent foramen ovale } \\
\text { closure }\end{array}$ & 10 & 10 & 12 \\
\hline Right reduction atrioplasty & 71 & 50 & 71 \\
\hline Right ventricular plication & 16 & 10 & 22 \\
\hline None & 10 & 30 & 0 \\
\hline Previous cardiac surgery (\%) & 6 & 10 & 33 \\
\hline
\end{tabular}

Thirty-seven patients of the 40 early survivors (93\%) were followed up for 2 to 136 months (mean $48.1 \pm 38.0$, median 34). There were no late deaths. There were no known recurrences of APMT. One patient had 3 episodes of tachycardia of uncertain mechanism, not requiring any treatment, during a 6-year period. Her initial ECG before surgery demonstrated preexcitation; this was absent after the operation, but her ECG after a 6-year follow-up suggested return of preexcitation. Six patients had new onset of $\mathrm{AFl} / \mathrm{F}$.

\section{Management of AVNRT $(\mathbf{n}=\mathbf{1 0})$}

No intervention for AVNRT $(n=3)$. Three patients did not have EA corrective surgery or intervention for AVNRT because of mild tricuspid regurgitation and minimal symptoms. One of them, an infant, died of diarrhea and dehydration not associated with an arrhythmia 1 month after electrophysiologic testing. Another patient who was followed up for 122 months had new onset of atrial flutter but not AVNRT. The third patient was unavailable for follow-up.

Surgical intervention for AVNRT $(n=7)$. Seven patients underwent intraoperative perinodal cryoablation for 


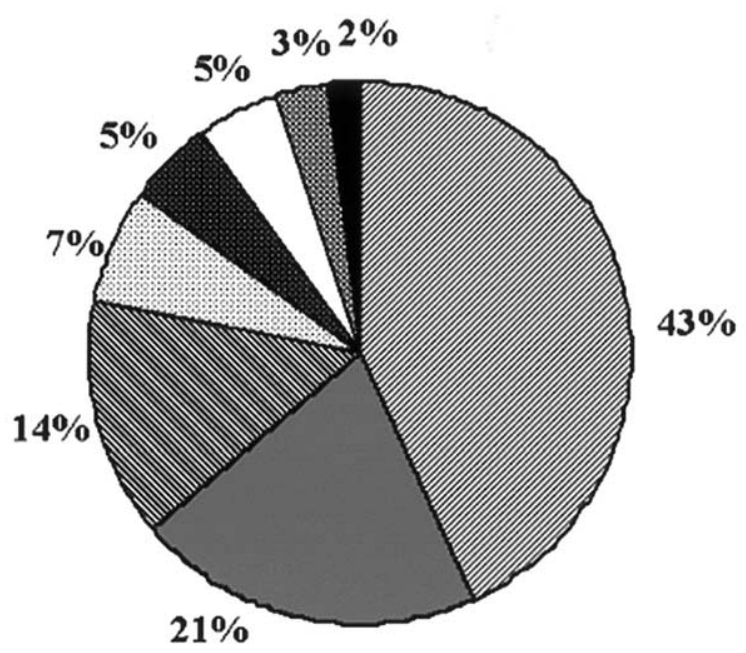

\begin{tabular}{|c|c|c|}
\hline QRight poster olateral & $\square$ Poster os eptal & $\mathbb{Q}$ Right posterior free wall \\
\hline 四 Anterolateral & 圈 Anteroseptal & $\square$ Right lateral free wall \\
\hline 图 Mahaim fiber & 口 PJRT & \\
\hline
\end{tabular}

Figure 3. Location of APs according to preoperative and/or intraoperative electrophysiology testing. PJRT, Permanent form of junctional reciprocating tachycardia.

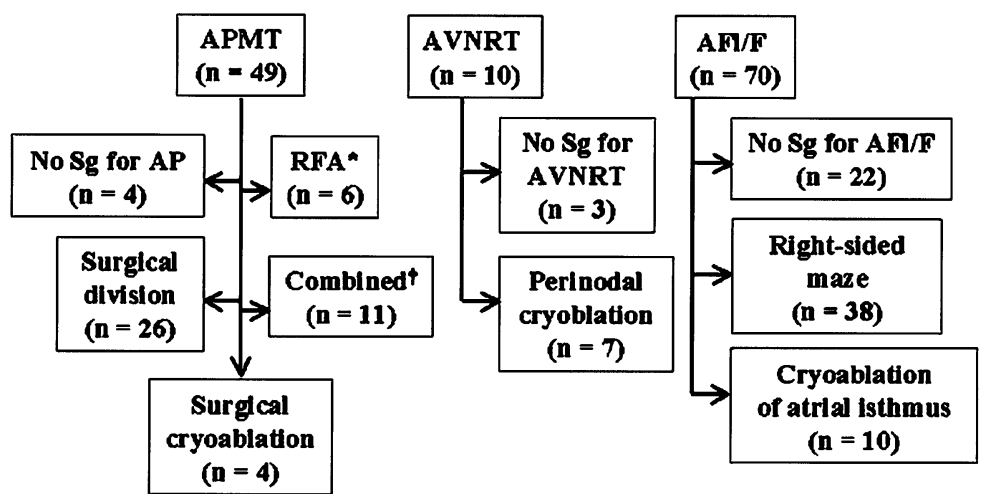

Figure 4. Management of supraventricular tachyarrhythmias according to their mechanisms. Some patients had more than one arrhythmia procedure at operation. Sg, Surgery; RFA, radiofrequency ablation. Asterisk indicates 2 patients in group subsequently underwent surgery for AP; dagger indicates combined surgical division and cryoablation.

AVNRT at the time of EA corrective surgery. No patient had complete heart block develop. There was 1 early death from intractable right ventricular failure; autopsy demonstrated extensive fibrosis of the anterior wall of the right ventricle. One patient had transient junctional ectopic tachycardia; the discharge ECG showed junctional rhythm. In the other 5 patients, normal conduction was seen on the discharge ECG.

All 6 early survivors have been followed up for 9 to 72 months (mean $57.3 \pm 24.3$, median 66). The last ECG of each showed sinus rhythm, and there has not been any recurrence of AVNRT. One patient had new-onset atrial flutter.

\section{Management of $\mathrm{AFl} / \mathrm{F}(\mathbf{n}=\mathbf{7 0})$}

No intervention for $\operatorname{AFl} / F(n=22)$. Twenty-two patients underwent EA corrective surgery for tricuspid regurgitation and associated defects without any intervention for the $\mathrm{AFl} / \mathrm{F}$; most of these patients were treated in the early part of this series, before effective surgical arrhythmia pro- 
cedures became available. There were 3 early deaths. Two patients died of ventricular arrhythmias; 1, a 44-year-old woman, underwent an autopsy that showed severe coronary artery disease and acute myocardial infarction. The third patient was the same one described in the AVNRT group who had right ventricular fibrosis.

Sixteen of the 19 early survivors (84\%) were followed up from 3 to 140 months (mean $57.2 \pm 47.7$ months, median 46 months). There were 2 late deaths, 3 and 23 months after operation, both of sudden cardiac arrest. Eight of the known 14 late survivors had no recurrence of arrhythmias. The remaining 6 patients had recurrent $\mathrm{AFl} / \mathrm{F}$ requiring antiarrhythmic drugs; 2 of the 6 subsequently underwent successful radiofrequency ablation of atrial flutter.

Right-sided maze procedure $(n=38)$. Thirty-eight patients underwent a concomitant right-sided maze procedure at the time of EA corrective surgery. There were 2 early deaths, both of myocardial infarction. No patients had complete heart block develop. Postoperative arrhythmias included transient junctional rhythm $(\mathrm{n}=3)$, transient $\mathrm{AFl} / \mathrm{F}$ $(\mathrm{n}=2)$, transient ventricular arrhythmia $(\mathrm{n}=1)$, and persistent atrial fibrillation $(\mathrm{n}=1)$. The discharge ECG demonstrated sinus rhythm $(\mathrm{n}=31)$, ectopic atrial rhythm (abnormal $\mathrm{P}$ axis, $\mathrm{n}=2)$, junctional rhythm $(\mathrm{n}=2)$, and atrial fibrillation $(\mathrm{n}=1)$.

Thirty-five of the 36 early survivors $(97 \%)$ were followed up from 6 to 87 months (mean $39.0 \pm 25.4$ months, median 38 months). There were no late deaths. Twenty-five patients $(71 \%)$ had no recurrence of arrhythmia. Ten patients (29\%) had recurrent AFl/F; 2 of them had chronic atrial fibrillation before the operation that persisted afterward. The remaining 8 patients had paroxysmal AFl/F before the operation that recurred from 1 to 15 months afterward. Two of the 8 patients underwent radiofrequency ablation for atrial flutter, but 1 patient had recurrent atrial flutter 13 months after ablation and a second attempted ablation was not successful. Two of the remaining 6 patients had only a single episode of recurrent $\mathrm{AFl} / \mathrm{F}$ at 3 and 12 months after operation, and they did not require any antiarrhythmic drugs. Four of the 6 patients required antiarrhythmic drugs because of more than one recurrent episode. At last follow-up ECG, only 2 of the 35 known late survivors $(6 \%)$ were still in $\mathrm{AFl} / \mathrm{F}$.

Cryoablation procedure $(n=10)$. Ten patients underwent a cryoablation procedure for treatment of $\mathrm{AFl} / \mathrm{F}$ at the time of EA corrective surgery. There were no early deaths. Postoperative arrhythmias included transient accelerated junctional rhythm reverting to atrial fibrillation $(n=1)$, atrial flutter requiring amiodarone $(\mathrm{n}=1)$, and high-grade (Mobitz II) AV block requiring insertion of a DDD pacemaker $(\mathrm{n}=1)$. The discharge ECG demonstrated sinus rhythm $(\mathrm{n}=8)$, atrial fibrillation $(\mathrm{n}=1)$, and dual-chamber pacemaker rhythm $(\mathrm{n}=1)$.
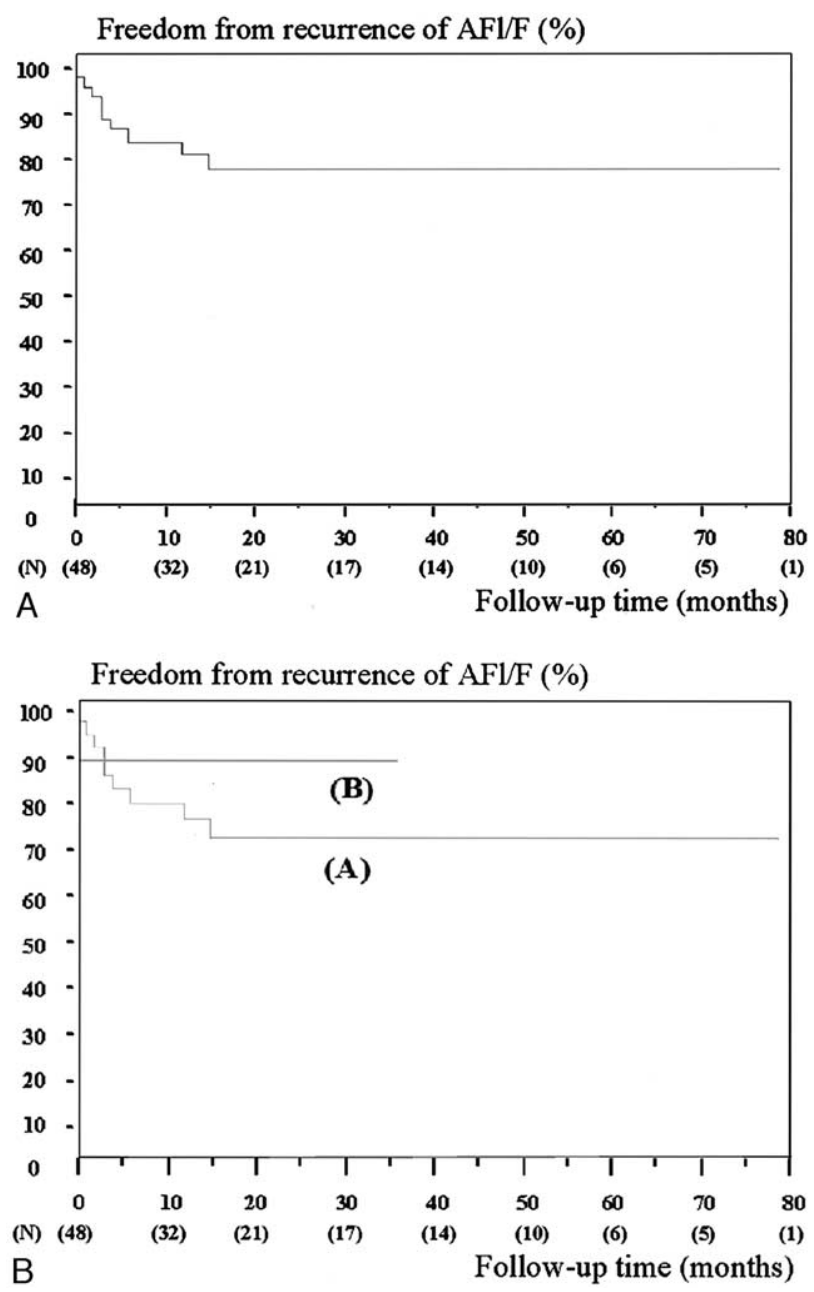

Figure 5. A, Freedom from recurrent AFI/F in all patients who underwent surgical management (right-sided maze procedure or cryoablation). B, Freedom from recurrent $A F I / F$ in patients who underwent right-sided maze procedure (line $A$ ) or cryoablation of the atrial isthmus (line $B, P=.5$ ).

Nine of the 10 early survivors were followed up from 6 to 60 months (mean $19.7 \pm 17.9$ months, median 14 months). There were no late deaths. Eight patients had no recurrence of $\mathrm{AFl} / \mathrm{F}$. One patient had chronic atrial fibrillation and was receiving amiodarone. One patient had new onset of ventricular tachycardia, which was successfully controlled by radiofrequency ablation.

The freedom from recurrent $\mathrm{AFl} / \mathrm{F}$ in the 48 patients who underwent either a right-sided maze or cryoablation procedures was $74.6 \% \pm 7.1 \%$ at mean follow-up of 34 months (Figure $5, A$ ). The rate of recurrence was not significantly different between the two procedures $(\mathrm{p}=0.5$; Figure $5, B)$. Overall, in the combined surgical intervention group, only 3 of the 44 late survivors followed up (7\%) still had chronic $\mathrm{AFl} / \mathrm{F}$. 


\section{Discussion}

Patients with EA may have a wide spectrum of symptoms, depending in large part on hemodynamic variables including severity of tricuspid regurgitation, degree of right-to-left shunting across a patent foramen ovale or atrial septal defect, and severity of right ventricular dysfunction. Symptoms are also influenced by presence of associated congenital cardiac anomalies, especially stenosis of the right ventricular outflow tract or pulmonary valve. Moreover, supraventricular tachyarrhythmias are commonly associated with this anomaly, causing palpitations, presyncope, syncope, or even sudden cardiac death. Such tachyarrhythmias are poorly tolerated because of the hemodynamic and anatomic abnormalities associated with EA. Current surgical procedures of tricuspid valve repair or replacement combined with correction of associated cardiac defects are highly successful and yield excellent early and late results. ${ }^{8-10}$ Management of supraventricular tachyarrhythmias associated with EA can be challenging. Nevertheless, it is clear that effective control of these arrhythmias is important for optimal patient outcome.

We agree with others ${ }^{17}$ who favor preoperative electrophysiologic testing for all patients with EA who have evidence of preexcitation on ECG or who have a history of wide-complex tachycardia or tachyarrhythmia of unknown type. Electrophysiologic testing can help to identify the presence, number, and characteristics of APs. In this review, concealed pathways were found in 11 additional patients with history of tachyarrhythmia who did not have evidence of preexcitation on ECG. Electrophysiologic testing can also identify possible associated mechanisms for supraventricular tachyarrhythmias such as AVNRT and easily inducible $\mathrm{AFl} / \mathrm{F}$. In this review, 18 patients had more than one mechanism for arrhythmia. Because surgical procedures are now available to treat these arrhythmias, their proper identification before EA corrective surgery is important for optimal rhythm control after operation.

Most APs in patients with EA with situs solitus and AV concordance are located on the right side $(98.5 \%$ in one registry's experience ${ }^{18}$ and $100 \%$ in this review). Preoperative electrophysiologic mapping and radiofrequency ablation of APs are complicated in patients with EA for several reasons. Apical displacement of the tricuspid valve away from the annulus creates tricuspid regurgitation and a broad area of atrialized right ventricle, which may prevent adequate catheter stability. The right atrium and right ventricle are characteristically enlarged, sometimes massively, distorting the anatomic landmarks and making the AV junction difficult to locate and target with catheters. Multiple APs are common ${ }^{18,19}$ (present in 9 of 49 patients in this review), and our intraoperative mapping studies and the preoperative mapping reports of others ${ }^{19,20}$ have shown that some APs are actually broad bands rather than the discrete, microscopic pathways typically found in patients without EA. In addition, a tendency toward development of atrial fibrillation during catheter manipulation can complicate mapping and ablation. These limitations principally account for the finding that there was complete concordance between the results of our preoperative and intraoperative mapping procedures regarding number and location of APs only $52 \%$ of the time.

Campbell and colleagues ${ }^{21}$ reported the results of a pediatric registry in which there was an acute success rate of 92\% for catheter ablation of all known APs (4462/4838 pathways); however, the acute success rate for left free wall APs was higher than for right free wall APs $(96.5 \%$ vs $88.6 \%$ ). Unlike these highly successful rates of catheter ablation of APs in the general population ( $>95 \%)$, the acute success rate of catheter ablation of APs in patients with EA is lower $(\leq 81 \%) .{ }^{18,19}$ Only 4 of 6 patients at our institution had successful ablation, and 11 of the patients in this review had previously undergone one to three unsuccessful attempts at catheter ablation elsewhere. Similar results have been reported from other institutions. In one report from a large pediatric radiofrequency ablation registry, the acute success rate (defined as absence of the arrhythmia on leaving the electrophysiologic laboratory) for catheter ablation of APs in 56 patients with EA was $81 \%$, and the 1-year success rate was only $57 \% .{ }^{18}$ In a smaller series, 16 of 21 patients with EA (76\%) had early ablation success after 1 to 3 sessions, but 4 of the 16 had arrhythmia recurrence during a mean follow-up of 22 months, for a late success rate of $57 \% .{ }^{19}$ Because the late success rate for catheter ablation of APs in EA is suboptimal, ${ }^{18,19}$ we favor primary reliance on surgical ablation, which has been highly effective in our experience and that of others. ${ }^{22-24}$ An ablation attempt may be made during preoperative electrophysiologic testing, but if success is not readily achieved, the APs can be remapped and ablated at the time of EA corrective surgery. In this review, there was no increase in early mortality when concomitant surgical ablation of APs was performed during EA corrective surgery ( 1 of 41 patients, $2.4 \%$ ).

Cox and colleagues ${ }^{25}$ reported successful cryosurgery of the perinodal tissues for AVNRT in 23 patients. Although we had a small number of patients with AVNRT, perinodal cryoablation for AVNRT was successful in all 10 patients with no complications and no recurrence of arrhythmia related to AVNRT at follow-up.

The most common supraventricular tachyarrhythmias seen in patients with EA are atrial flutter and atrial fibrillation $(70 / 129,54 \%$ in this review). $\mathrm{AFl} / \mathrm{F}$ is more frequent in older patients; the median age was 35 years compared with 16 years for APMT and 18 years for AVNRT. AFl/F is also more common after previous cardiac surgery; new-onset $\mathrm{AFl} / \mathrm{F}$ developed during follow-up in 6 patients after operation for APMT and in 1 patient after operation for AVNRT. The large size of the right atrium in EA and the 
presence of surgical incisions are thought to provide the substrates for these arrhythmias. At operation, they are addressed by right reduction atrioplasty and by placing surgical incisions or cryoablation blocking lines to prevent atrial reentry circuits. Before the availability of surgical arrhythmia procedures, some patients in this review had no further $\mathrm{AFl} / \mathrm{F}$ after $\mathrm{EA}$ corrective surgery in which the tricuspid valve was made competent and a right reduction atrioplasty was performed ( 8 of 14 survivors, 57\%). However, freedom from arrhythmia recurrence was improved with the addition of a right-sided maze or cryoablation procedure $(33 / 44,75 \%, P=.06)$. It is encouraging that even when there was a recurrence, chronic atrial fibrillation could be reduced to $7 \%$ by the adjunctive use of antiarrhythmic drugs, catheter ablation, or both.

The addition of one or more concomitant arrhythmia procedures at the time of EA corrective surgery did not increase the early mortality in this study $(4.8 \%)$ relative to the overall mortality rate of $6.8 \%$ for our overall series of 498 patients undergoing operation for EA (unpublished observations).

\section{Conclusions}

Electrophysiologic testing plays an important role in the diagnosis and management of patients with EA and supraventricular tachyarrhythmias. Therefore all patients with documented tachycardia or a history of palpitations should undergo preoperative electrophysiologic testing regardless of evidence of preexcitation. Because the late success rate for catheter ablation of APs in EA is suboptimal, we favor primary reliance on surgical ablation. Concomitant arrhythmia procedures can be combined with EA corrective surgery without increase in early mortality; we conclude they should be added to EA repairs for all patients who have supraventricular tachyarrhythmias. Surgical intervention for APMT and AVNRT yielded excellent freedom from recurrence of these arrhythmias. Surgical intervention for AFl/F yielded freedom from late recurrence in $75 \%$ of patients, but after adjunctive medical or catheter therapy only $7 \%$ of late survivors were still in AFl/F.

We gratefully acknowledge the statisticians at the Mayo Clinic Center for Patient Oriented Research for statistical assistance.

\section{References}

1. Schiebler GL, Gravenstein JS, Van Mierop LH. Ebstein's anomaly of the tricuspid valve. Translation of original description with comments. Am J Cardiol. 1968;22:867-73.

2. Mann RJ, Lie JT. The life story of Wilhelm Ebstein (1836-1912) and his almost overlooked description of a congenital heart disease. Mayo Clin Proc. 1979;54:197-204.

3. van Son JA, Konstantinov IE, Zimmermann V. Wilhelm Ebstein and Ebstein's malformation. Eur J Cardiothorac Surg. 2001;20:1082-5.

4. Anderson KR, Zuberbuhler JR, Anderson RH, Becker AE, Lie JT.
Morphologic spectrum of Ebstein's anomaly of the heart: a review. Mayo Clin Proc. 1979;54:174-80.

5. Oh JK, Holmes DR Jr, Hayes DL, Porter CB, Danielson GK. Cardiac arrhythmias in patients with surgical repair of Ebstein's anomaly. $J$ Am Coll Cardiol. 1985;6:1351-7.

6. Olson TM, Porter CB. Electrocardiographic and electrophysiologic findings in Ebstein's anomaly. Pathophysiology, diagnosis, and management. Prog Pediatr Cardiol. 1993;2:38-50.

7. Mair DD. Ebstein's anomaly: natural history and management. $J$ Am Coll Cardiol. 1992;19:1047-8.

8. Danielson GK, Driscoll DJ, Mair DD, Warnes CA, Oliver WC Jr. Operative treatment of Ebstein's anomaly. J Thorac Cardiovasc Surg. 1992;104:1195-202.

9. Danielson GK. Ebstein's anomaly: In: Baue A, Geha AS, Hammond GL, Laks H, Naunheim KS, editors. Glenn's thoracic and cardiovascular surgery. Stamford (CT): Appleton \& Lange; 1996, p. 1359-68.

10. Kiziltan HT, Theodoro DA, Warnes CA, O'Leary PW, Anderson BJ, Danielson GK. Late results of bioprosthetic tricuspid valve replacement in Ebstein's anomaly. Ann Thorac Surg. 1998;66:1539-45.

11. Shiina A, Seward JB, Tajik AJ, Hagler DJ, Danielson GK. Twodimensional echocardiographic-surgical correlation in Ebstein's anomaly: preoperative determination of patients requiring tricuspid valve plication vs replacement. Circulation. 1983;68:534-44.

12. Shiina A, Seward JB, Edwards WD, Hagler DJ, Tajik AJ. Twodimensional echocardiographic spectrum of Ebstein's anomaly: detailed anatomic assessment. J Am Coll Cardiol. 1984;3:356-70.

13. Seward JB. Ebstein's anomaly: ultrasound imaging and hemodynamic evaluation. Echocardigraphy. 1993;10:641-64.

14. Greason KL, Dearani JA, Theodoro DA, Porter CJ, Warnes CA, Danielson GK. Surgical management of atrial tachyarrhythmias associated with congenital cardiac anomalies: Mayo Clinic experience. Semin Thorac Cardiovasc Surg Pediatr Card Surg Annu. 2003;6:59-71.

15. Dearani JA, Danielson GK. Ebstein's anomaly of the tricuspid valve. In: Mavroudis C, Backer CL, editors. Pediatric cardiac surgery. 3rd ed. Philadelphia: Mosby; 2003. p. 524-36.

16. Theodoro DA, Danielson GK, Porter CJ, Warnes CA. Right-sided maze procedure for right atrial arrhythmias in congenital heart disease. Ann Thorac Surg. 1998;65:149-54.

17. Huang CJ, Chiu IS, Lin FY, Chen WJ, Lin JL, Lo HM, et al. Role of electrophysiological studies and arrhythmia intervention in repairing Ebstein's anomaly. Thorac Cardiovasc Surg. 2000;48:347-50.

18. Reich JD, Auld D, Hulse E, Sullivan K, Campbell R. The Pediatric Radiofrequency Ablation Registry's experience with Ebstein's anomaly. Pediatric Electrophysiology Society. J Cardiovasc Electrophysiol. 1998;9:1370-7.

19. Cappato R, Schluter M, Weiss C, Antz M, Koschyk DH, Hofmann T, et al. Radiofrequency current catheter ablation of accessory atrioventricular pathways in Ebstein's anomaly. Circulation. 1996;94:376-83.

20. Okishige K, Azegami K, Goseki Y, et al. Radiofrequency ablation of tachyarrhythmias in patients with Ebstein's anomaly. Int J Cardiol. 1997;60:171-80.

21. Campbell RM, Strieper MJ, Frias PA, Danford DA, Kugler JD. Current status of radiofrequency ablation for common pediatric supraventricular tachycardias. J Pediatr. 2002;140:150-5.

22. Misaki T, Watanabe G, Iwa T, Watanabe Y, Mukai K, Takahashi M, et al. Surgical treatment of patients with Wolff-Parkinson-White syndrome and associated Ebstein's anomaly. J Thorac Cardiovasc Surg. 1995;110:1702-7.

23. Lazorishinets VV, Glagola MD, Stychinsky AS, Rudenko MN, Knyshov GV. Surgical treatment of Wolf-Parkinson-White syndrome during plastic operations in patients with Ebstein's anomaly. Eur J Cardiothorac Surg. 2000;18:487-90.

24. Bouboulis N, Dougenis D, Campbell RW, Hilton CJ. Surgical Implications in the current treatment of Wolff-Parkinson-White syndrome. World J Surg. 2002;26:122-8.

25. Cox JL, Ferguson TB Jr, Lindsay BD, Cain ME. Perinodal cryosurgery for atrioventricular node reentry tachycardia in 23 patients. $J$ Thorac Cardiovasc Surg. 1990;99:440-50. 